\title{
VIOLAÇÕES AOS DIREITOS HUMANOS E MEGAEVENTOS: UMA ANÁLISE DA COPA DO MUNDO DE 2014 NA PERSPECTIVA DA ASSINCRONIA DO DIREITO
}

\author{
HUMAN RIGHTS VIOLATIONS AND MAJOR EVENTS: AN ANALYSYS \\ OF THE WORLD CUP 2014 IN A VIEW OF RIGHT ASYNCHRONY
}

\begin{abstract}
SUMÁRIO: Introdução. 1 Cidade de Exceção: uma análise da Filosofia de Giorgio Agamben na Perspectiva da Copa do Mundo de 2014 no Brasil; 2 Direito Fundamental à moradia adequada sob a ótica dos megaeventos esportivos; 3 Os Megaeventos Esportivos na perspectiva da Assincronia do Direito; Conclusão; Referências.
\end{abstract}

RESUMO: Este artigo tem como objetivo principal analisar as violações aos direitos humanos, sobretudo ao direito à moradia adequada, causadas pela incorreta execução e aplicação dos projetos das obras da Copa do Mundo de 2014 (e das Olimpíadas de 2016) no Brasil. Para tanto, o texto discorrerá brevemente acerca do fenômeno da exceção, trabalhado por Giorgio Agamben, afirmando que este vem sendo o parâmetro geral do governo no que concerne à legislação utilizada como justificadora de remoções forçadas, desapropriações irregulares e violações ao instituto jurídico da posse. Por fim, far-se-á uma análise do fenômeno da assincronia do direito, estudado por Mireille-Delmas Marty, no sentido de afirmar que as obras vinculadas aos megaeventos esportivos no Brasil corroboram para o recrudescimento de tal fenômeno.

Palavras-chave: Copa do Mundo. Estado de Exceção. Direito à moradia. Assincronia.

ABSTRACT: This article aims to analyze the main human rights violations, particulary the right to adequate housing, caused by the incorrect execution and implementation of World Cup 2014 (and the 2016 Olympics) projects of woks (and the 2016 Olympics) in Brazil. Therefore, the text will discuss briefly about the phenomenon of exception, worked for Giorgio Agamben, stating that this has been the general parameter of the government regarding the legislation used as justifying the forced removal, irregular expropriation and violations of legal institution of ternure. Finally, there will be an analysis of the phenomenon of asynchrony law, studied by Mirelle Delmas-Marty, in affirming that the constructions related to the mega sporting events in Brazil contributes for the occurrence of such phenomenon.

Key-words: World Cup. State of Exception. Right to adequate housing. Asynchrony.

\section{INTRODUÇÃO}

No contexto globalizado em que o mundo se insere, a escolha de determinado país como sede de um megaevento esportivo qualifica-se como algo relevante, uma vez que não só confere destaque ao Estado sede no plano internacional como gera, em âmbito interno, oportunidades de estimular iniciativas e coletar investimentos que possam melhorar a qualidade de vida da população. Entretanto, diante da fase neoliberal do sistema capitalista, no qual grandes conglomerados econômicos e patrocinadores dos eventos priorizam e valorizam a lógica de acumulação de capital, tem-se que os acontecimentos esportivos não são vistos como meios de servir ao povo e sim como uma justificativa para benefícios próprios e para a desvalorização de imperativos humanos sociais vitais.

Neste sentido, surgem, em diversos instrumentos normativos justificadores desses megaeventos, inúmeras violações a determinações legais e constitucionais, violações estas que aparentam ter aspecto de legalidade. Tal fenômeno é o que Giorgio Agamben (2004) denomina de "estado de exceção". Para ele, as sociedades atuais vivem nesse permanente estado, em uma espécie de guerra interna que permite a aniquilação não só de adversários políticos, como também de categorias inteiras de cidadãos que, por algum motivo, não se encaixam nas necessidades do sistema político 
vigente. A violação constante de direitos e garantias constitucionalmente previstos escancara não só este lugar de "não direito" como também o autoritarismo de instituições estatais, revelando o caráter não democrático das "democracias" dos Estados neoliberais (WOOD, 2003).

Desta forma, o presente trabalho pretende abordar o evento que o Brasil sediará em 2014, a Copa do Mundo, apontando algumas das diversas violações aos direitos humanos perpetradas pelo Estado. Dar-se-á ênfase, sobretudo, às já constatadas ofensas aos direitos de moradia, com desapropriações irregulares, nítido desrespeito ao instituto da posse e remoções forçadas feitas em diversos estados brasileiros utilizando, como escopos legais, normas promulgadas recentemente em função do megaevento.

Pretende-se, outrossim, demonstrar de que maneira o fenômeno da assincronia do direito recrudesce frente ao contexto apresentado. Tal fenômeno, estudado pela jurista francesa Mireille Delmas-Marty (2004) se manifesta através da diferença de velocidades de evolução e integração dos diversos setores normativos, especialmente entre o direito econômico e o direito dos direitos humanos. Almeja-se demonstrar que, no momento em que o sistema desaplica dispositivos jurídicos instituídos por ele próprio, em função de serem uma barreira ou uma ameaça à manutenção do status quo, há contribuição para a inefetividade dos direitos humanos, em comparação com a efetiva aplicação de outros setores normativos, como é o caso dos direitos econômicos.

Tal análise será realizada através de um estudo dos impactos constatados e documentados por movimentos populares (Dossiê da Articulação Nacional dos Comitês Populares da Copa e Dossiê do Comitê Popular da Copa e Olimpíadas do Rio de Janeiro), bem como das frequentes e recentes notícias e decisões de tribunais competentes acerca dos processos de desapropriação ocorridos em função do megaevento.

Assim, o artigo dividir-se-á em três partes: a primeira delas tratará do surgimento das chamadas "Cidades de Exceção", remontando às ideias de Giorgio Agaben (2004) de instrumentos normativos promulgados em função da Copa do Mundo de 2014 (e também das Olimpíadas de 2016) que, com sua aparência de legalidade, justificam violações aos direitos humanos consagrados constitucional e internacionalmente (PARTE 1). Posteriormente, far-se-á uma breve análise das violações aos direitos de moradia dos povos atingidos pelas obras da Copa, explicando e exemplificando de que modo estão ocorrendo desapropriações irregulares, remoções forçadas e ofensas ao instituto da posse (PARTE 2). Por fim, tratar-se-á do fenômeno da assincronia do direito no Brasil e de que modo os legados da Copa poderão contribuir para o recrudescimento deste (PARTE 3).

\section{CIDADE DE EXCEÇÃO: UMA ANÁLISE DA FILOSOFIA DE GIRGIO AGAMBEN NA PERSPECTIVA DA COPA DO MUNDO DE 2014 NO BRASIL}

"O problema fundamental em relação aos direitos do homem, hoje, não é tanto o de justifica-los, mas o de protegê-los." Assim preconiza Norberto Bobbio (2004, p.23) asseverando que os direitos do homem não são um mero dado da natureza. Pelo contrário, são um construído jurídico voltado para o aprimoramento político da convivência na coletividade. Todavia, o direito que inicialmente possibilitou a organização do homem em sociedade e tornou sua vida mais segura, hoje, se apresenta incapaz de assegurar esses objetivos, de modo que o Estado, inúmeras vezes, volta-se contra seus próprios cidadãos.

Neste contexto, emerge a análise de Giorgio Agamben (2004) do denominado "estado de exceção". De acordo com o teórico, tal estado tende a se apresentar como 
paradigma de governo dominante na política contemporânea, sendo que a tradição dos oprimidos ensina que o "estado de exceção", paradoxalmente é a regra geral, consubstanciando-se como uma técnica de governo que confere forma legal àquilo que não pode ter forma legal.

Tal constatação de Agamben é notada atualmente, na medida em que o "estado de exceção" deixou de ser a exceção para se tornar a regra dos governos. No Brasil, é possível constatar a existência de tal estado, sobretudo quando se analisam questões relativas não só à Copa do Mundo de 2014 como também às Olimpíadas de 2016. O desrespeito sistemático à legislação vigente, típico do "estado de exceção" é legitimado em nosso país através de atos e decretos novos, feitos unicamente em função dos megaeventos esportivos e que desrespeitam uma série de leis e outras normas do ordenamento jurídico.

$\mathrm{Na}$ realidade, megaeventos como a Copa do Mundo ou as Olimpíadas possuem, obviamente, como motivação primordial o estímulo e incentivo ao esporte e aos atletas profissionais. Todavia, sintomas e constatações do legado dos eventos em outros países ${ }^{1}$ que os sediaram levam à conclusão de que o que está em jogo não é somente o esporte, mas também o grande rol de possibilidades econômicas vinculado aos eventos.

A FIFA (Federação Internacional das Associações de Futebol) tem funcionado como intermediadora dos interesses de empresas e instituições financeiras que possuem interesse nos lucros gerados pelos eventos. Através de contratos entabulados com os países que recepcionam os eventos, a federação realiza exigências que além de gerar um excessivo ônus público em detrimento do capital privado, normalmente se processam em contradição com o ordenamento jurídico nacional. Desta forma, a mudança da legislação interna dos países é de suma importância para aqueles que somente tem interesses em ganhos econômicos com os eventos, uma vez que assim podem fazer valer as suas regras sobre determinados assuntos (HOSHINO E GORSDORF, 2011).

Neste sentido, surgem as denominadas "Cidades de Exceção". Nos diversos níveis federativos uma infinidade de medidas provisórias, decretos legislativos, leis votadas sem o conhecimento prévio dos cidadãos, portarias, resoluções e atos administrativos criados unicamente em função da especulação gerada pelos megaeventos fazem com que inúmeros diplomas legais caduquem diante dos interesses dos patrocinadores dos megaeventos. Há, portanto, uma clara sobreposição do interesse privado em relação ao interesse público, configurando-se aí a inconstitucionalidade da exceção, a partir da violação de princípios constitucionais e internacionais.

Para exemplificar tal constatação, pode-se destacar o denominado Ato Olímpico (Lei $\left.n^{\circ} .12 .035 / 09\right)$ que estabelece regras especiais para a realização dos Jogos Olímpicos de 2016 no Brasil. O próprio processo de criação do instrumento normativo já se deu nos moldes da exceção: a lei só passaria a viger se a cidade do Rio de Janeiro fosse escolhida como sede dos jogos, sendo que, antes mesmo da reunião de definição da sede do evento, o Congresso Nacional já havia aprovado o Ato Olímpico, garantindo uma série de prerrogativas para o Comitê Olímpico Internacional. Dentre essas, destacase a dispensa da exigência de vistos de ingresso no território nacional para estrangeiros responsáveis pela organização dos jogos e o controle, fiscalização e repressão de atos

\footnotetext{
${ }^{1}$ De acordo com Hoshino e Gorsdorf (2011) o padrão observado é que a recepção de um megaevento autoriza também megaviolações de direitos fundamentais e megairregularidades. Isso é constatado nas edições anteriores desses eventos esportivos: higienização social na África do Sul, remoções maciças em Pequim, especulação imobiliária em Barcelona, contribuições para o superendividamento na Grécia, dentre outros legados negativos.
} 
ilícitos que infringirem direitos sobre os símbolos relacionados aos Jogos Olímpicos de $2016^{2}$.

Ainda, o art. $5^{\circ}$ dessa mesma lei possibilita a revisão, pelo Poder Executivo, de instrumentos unilaterais ou bilaterais que tenham por objeto, de forma precária ou não, bens, imóveis ou equipamentos pertencentes à União ou às suas autarquias, indispensáveis para a realização dos jogos das Olimpíadas, assegurada justa indenização nos casos em que couber. Todavia, tal disposição legal contraria as determinações da Lei Federal $n^{\circ} 11.124 / 05$, que, de maneira geral, determina que a utilização prioritária de terrenos do Poder Público deve ser para a implantação de projetos habitacionais de interesse social.

Neste mesmo viés, consoante destaca o documento elaborado pela Articulação Nacional dos Comitês Populares da Copa, em âmbito estadual e municipal, leis orgânicas e Constituições Estaduais são confrontadas por decretos e resoluções elaborados somente para atender aos anseios gerados pelos megaeventos. No Rio de Janeiro, por exemplo, contrariando as disposições da lei que versa sobre o Sistema Nacional de Habitação de Interesse Social (Lei no. 11.124/05), o Decreto Municipal n. 30.379/09 determina que o Poder Executivo "envidará todos os esforços necessários no sentido de possibilitar a utilização de bens pertencentes à administração pública municipal, ainda que ocupado por terceiros, indispensáveis à realização dos jogos.”.

Além disso, a Lei Geral da Copa (Lei no . 12.663/2012), promulgada em 2012 pela Presidente da República completa o cenário de exceção, a partir do momento em que, não só cria um rol taxativo de tipos penais exclusivamente para delitos cometidos em função da Copa do $\mathrm{Mundo}^{3}$, como possibilita a concessão de isenções fiscais de valores bilionários à FIFA ${ }^{4}$.

Estes são apenas alguns dos exemplos que levam à conclusão da veracidade, em terrae brasilis, do "estado de exceção", denominado, consoante já fora referido de "cidade de exceção", a partir do momento em que a suspensão de direitos transforma-se em técnica de governo, fazendo com que ordem e desordem jurídica se confundam. Percebe-se que não há interesse ou preocupação na realização de um diálogo entre a legislação vigente e aquilo que foi criado em função dos megaeventos esportivos.

Sobretudo no campo habitacional, os eventos funcionam como meras justificativas para criar a chamada "segregação espacial", no sentido de "limpar" das

\footnotetext{
${ }^{2}$ Os artigos $2^{\circ}$ e art. $7^{a}$ da Lei $n^{\circ} .12 .035 / 09$ trazem essas prerrogativas.

${ }^{3}$ Neste caso, é pertinente destacar a experiência sul-africana. Para a recepção da Copa do Mundo de 2010, a África do Sul criou 56 Tribunais Especiais da Copa, nos quais a aplicação da legislação penal mostrouse amplamente desproporcional: penas de mais de dez anos por furtos de câmeras fotográficas e distinções entre brancos e negros. No Brasil, apesar do projeto de Lei Geral da Copa (Projeto de Lei n.2.330/2011) em seu art. 37 trazer a possibilidade de criação de Juizados Especiais, varas, turmas ou câmaras especializadas para processamento e julgamento de causas relacionadas ao evento esportivo, tal disposição não foi aprovada na votação do projeto de lei e, em função disso, a Lei Geral da Copa não prevê a criação de tribunais de exceção durante Copa do Mundo (HOSHINO e GORDSDORF, 2011).

${ }^{4}$ Vide neste caso a curiosidade destacada por Hoshino e Gordsdorf (2011) acerca da Lei n. ${ }^{\circ}$ 12.462/2011, que trata do RDC - Regime Diferenciado de Contratações Públicas. Segundo observam os autores, a brecha aberta para a criação desta lei veio com a Medida Provisória n.527 de 2011, sendo que antes da aprovação pelo Congresso Nacional desta MP, outras três tentativas do governo e de sua bancada no Congresso haviam sido feitas através de outras MP's, sendo que duas delas perderam sua eficácia e uma delas foi rejeitada. O relevante, contudo, é que a trajetória de insistência e posterior aprovação e conversão da MP em lei refere-se a um ato normativo que regulamento o destino de aproximadamente $\mathrm{R} \$$ 112 bilhões.

${ }^{5}$ Neste sentido, além de o direito básico à moradia ser penalizado com desapropriações massivas e irregulares, acaba-se criando duas cidades, sendo uma delas a "cidade para turista ver" ou a denominada "city marketing", uma cidade "modelo", com construções cujo intuito é o de atender às demandas do capital. Tal fenômeno ocorreu também na África do Sul, sede da Copa do Mundo de 2010, com a
} 
terras públicas e de áreas de interesse imobiliário as ocupações populares e estimular a especulação mercadológica nestes terrenos. Assim, a violação de direitos e garantias fundamentais, como é o caso do direito fundamental à moradia, escancara o lugar de "não direito" em que se vive, sendo que o autoritarismo manifestado por instituições estatais demonstra a antítese estrutural entre democracia e capitalismo (WOOD, 2008), revelando o caráter não democrático das "democracias" dos Estados capitalistas em sua fase neoliberal.

\section{DIREITO FUNDAMENTAL À MORADIA ADEQUADA SOB A ÓTICA DOS MEGAEVENTOS ESPORTIVOS}

A ocupação do espaço urbano é uma das maiores mazelas sociais do Brasil. O grande crescimento urbano, intensificado ao longo do século XX, é marcado pela ausência de planejamento e de políticas públicas capazes de resolver, ou no mínimo amenizar, o déficit habitacional, a periferização e o deslocamento autoritário de populações ilegais, principalmente das classes economicamente menos favorecidas, $\mathrm{o}$ que gera um território urbano marcado pela desigualdade e exclusão social.

De acordo com dados do IBGE (Instituto Brasileiro de Geografia e Estatística), em 2010, no Brasil, cerca de 11,42 milhões de pessoas estavam morando em favelas, palafitas ou outros assentamentos irregulares (WERNECK e LEAL, 2011). Comparando-se com pesquisas realizadas há vinte anos, a quantia de pessoas habitando em áreas como as referidas e, em condições precárias, quase dobrou ${ }^{6}$.

Em razão, disso, pode-se afirmar que, embora consagrado não só constitucionalmente $^{7}$, mas também em pactos internacionais ${ }^{8}$ ratificados pelo Estado brasileiro, o direito à moradia adequada além de não ser aplicado de maneira efetiva no país, vem sendo ameaçado pelas diversas obras da Copa do Mundo e das Olímpiadas. O direito à moradia adequada não se resume apenas a um teto, pelo contrário, inclui uma série de outros fatores, como a disponibilidade de serviços de infraestrutura e equipamentos públicos, habitabilidade, localização adequada e, dentre outros, segurança da posse.

É justamente como uma violação neste último quesito que se encontram os problemas vinculados às obras dos megaeventos aludidos, segundo demonstram os Dossiês do Comitê Popular da Copa e das Olimpíadas do Rio de Janeiro e da Articulação Nacional dos Comitês Populares da Copa. Desapropriações realizadas irregularmente, remoções forçadas de 150.000 a 170.000 (DOSSIÊ MEGAEVENTOS E VIOLAÇÕES DE DIREITOS HUMANOS NO BRASIL, 2011) pessoas e nítidas violações ao instituto da posse e de sua função social apresentam-se somente como o início dos reflexos da realização dos megaeventos no Brasil.

denominada higienização em massa, no qual se buscava, sob o pretexto da realização do megaevento, deixar as ruas "limpas" da pobreza. (Hoshino e Gordsdorf, 2011).

6 A comparação com levantamento realizado há vinte anos indica que quase dobrou no período a proporção de brasileiros que moram nessas áreas, em condições precárias. Em 1991, 4,48 milhões de pessoas $(3,1 \%$ da população) viviam em assentamentos irregulares, número que aumentou para 6,53 milhões (3,9\%) no Censo de 2000 (WERNECK e LEAL, 2011).

$7 \mathrm{O}$ art. $6^{\circ}$ da Constituição Federal determina que "são direitos sociais a educação, a saúde, a alimentação, o trabalho, a moradia, o lazer, a segurança, a previdência social, a proteção à maternidade e à infância, a assistência aos desamparados, na forma desta Constituição”.

$8 \mathrm{O}$ direito à moradia adequada foi reconhecido como direito humano na Declaração Universal dos Direitos do Homem de 1948. 
De acordo com a relatora mundial da ONU, Raquel Rolnik ${ }^{9}$, consoante observação de casos ocorridos em outros países anfitriões de eventos olímpicos e/ou futebolísticos, como é o caso da África do Sul, da China e de outras localidades, as violações aos direitos de moradia se dão nas modalidades anteriormente referidas, sendo os alvos prioritários aquelas pessoas sem títulos de propriedade registrados em cartório e que habitam em favelas, ocupações irregulares e assentamentos informais, ou seja, locais onde a população pobre produziu sua própria moradia.

Neste sentido inclusive, é pertinente destacar que moradia não é um direito que abrange somente o proprietário de determinado terreno ou bem. Pelo contrário, qualquer indivíduo que se encontre ocupando algum imóvel deverá ter o seu direito à moradia tutelado. Neste caso, por exemplo, encontram-se os indivíduos que são meros possuidores de determinado bem ou terreno e, embora não possuam a propriedade do imóvel, possuem domínio fático sobre ele, devendo, portanto, ter seus direitos e garantias assegurados em casos de desapropriação ou de remoção.

Doutrinariamente (ROSENVALD et FARIAS, 2011, p.41) a posse é considerada um direito subjetivo, alicerçado em uma situação fática, sendo que o ordenamento jurídico pátrio confere ao possuidor o poder de satisfazer o direito fundamental de moradia, já assegurado constitucional e internacionalmente. Em geral, no meio doutrinário, distinguem-se três tipos de posse: posse real ${ }^{10}$; posse obrigacional e posse fática. Este última, contudo, é a relevante em grande parte dos casos de violação observados em função dos megaeventos.

A posse fática independe de qualquer relação jurídica real ou obrigacional que lhe conceda substrato, uma vez que ela emana de uma situação fática e existencial de apossamento e ocupação de determinado bem ou imóvel (ROSENVALD et FARIAS, 2011, p.47). Neste sentido, aqui se consubstancia a denominada função social da posse, uma vez que o interesse do ordenamento jurídico não é mais tanto o de conceituar ou justificar a estrutura de seus institutos, mas de direcionar seu papel e sua missão para atender aos anseios da coletividade.

Apesar de o Código Civil de 2002 acolher a teoria objetiva da posse de Ihering $^{11}$, a Constituição Federal de 1988, através da previsão do direito social à moradia e do acesso aos bens vitais mínimos hábeis a conceder a dignidade da pessoa humana, tutela a posse como direito especial pela própria relevância de possuir. Assim, diante do processo de constitucionalização do direito civil, o instituto da posse não pode ser estudado sem a adequação à ordem constitucional.

Neste viés, o princípio da dignidade da pessoa humana deve permear a análise da posse, sendo visto como vetor de ponderação de lides, valorizando-se os efeitos possessórios por si e não em função da propriedade. A função social da posse, portanto, deve ser considerada de acordo com a situação fática de um possuidor sobre a coisa que

\footnotetext{
${ }^{9}$ Tais informações encontram-se disponíveis na entrevista dada pela arquiteta Raquel Rolnik acerca dos legados das Copas dos Mundo para seus países sede. A entrevista na íntegra encontra-se em no endereço eletrônico: https://raquelrolnik.wordpress.com/tag/copa-do-mundo/. Acesso em 17 de abril de 2014.

${ }^{10}$ De acordo com Nelson Rosenvald e Cristiano Chaves de Farias (2011) a posse real ocorre quando o proprietário é possuidor de seu bem. Neste caso, a posse configura-se como um direito real, disciplinado pelo art. 1.196 do Código Civil de 2002, e sendo fundamentalmente jurídica, uma vez que o proprietário manifesta o domínio sobre o bem por um direito real, que se visualiza na situação possessória. O segundo tipo de posse, a posse obrigacional, por sua vez, é vislumbrada através de uma relação jurídica obrigacional, sendo esta última o fato jurídico que atribui a posse aos indivíduos.

${ }^{11}$ Salienta-se, contudo, que embora tenha o Código Civil de 2002 se filiado à teoria objetiva da posse, de Ihering, percebe-se a adoção da teoria subjetiva da posse no tocante à usucapião como modo aquisitivo da propriedade que demanda o animus domini típico da teoria de Savigny (ROSENVALD et FARIAS, 2011, p.47).
} 
o titular patrimonial desvinculou de qualquer função social, sendo então um estímulo à moradia, uma vez que o acesso à posse pode ser considerado um instrumento de redução de desigualdades sociais e de promoção de uma justiça retributiva.

Todavia, em inúmeros casos envolvendo as obras da Copa do Mundo, a função social da posse não é respeitada. Nos casos de desapropriação, por exemplo, a legislação ${ }^{12}$ determina que o proprietário que for alijado de sua propriedade deverá receber uma justa indenização. Entretanto, como a realidade social é muito mais complexa e dinâmica que as disposições legais, a indagação constante que surge é: como ficam os possuidores em casos de desapropriação?

De acordo com dispositivos legais do ordenamento jurídico, em caso de utilidade pública, necessidade ou interesse social ${ }^{13}$, o Poder Público é autorizado à, mediante aviso anterior, manifestar o interesse na área e proceder a desapropriação, pagando ao proprietário uma justa indenização pelo local (FILHO, 2010, p.364). Contudo, no caso dos projetos vinculados aos megaeventos esportivos no Brasil, o comum é ver situações de comunidades inteiras que se formam sobre terrenos de propriedade de terceiros, os quais se encontram abandonados e sem cumprir sua função social, de modo que os prejudicados em razão da desapropriação não são os proprietários, mas os possuidores fáticos da área.

Em casos apontados por documentários (ESPN, 2011) ou documentos redigidos por movimentos sociais (DOSSIÊ MEGAEVENTOS E VIOLAÇÕES DE DIREITOS HUMANOS NO BRASIL, 2011 e DOSSIÊ MEGAEVENTOS E VIOLAÇÕES DE DIREITOS HUMANOS NO RIO DE JANEIRO, 2012), observa-se que, em diversas situações, o proprietário do terreno a ser desapropriado é desconhecido e, os moradores da região, são apenas possuidores - em geral irregulares - dos imóveis ali construídos. Neste caso, a lei ${ }^{14}$ determina que o Poder Público, em procedimento judicial, deverá realizar o depósito em juízo do valor do imóvel, sendo que somente em ação autônoma discutir-se-á o valor depositado e os beneficiários deste valor, pois na ação de desapropriação, não há espaço para discussões sobre domínio.

Consoante demonstram os Dossiês do Comitê Popular da Copa e das Olimpíadas do Rio de Janeiro (2012) e da Articulação Nacional dos Comitês Populares da Copa (2011), em alguns casos vinculados às obras da Copa do Mundo e das Olimpíadas além de os procedimentos anteriores à desapropriação serem violados, como é o caso do direito à informação, muitos moradores estão sendo retirados de suas casas, sem um prazo adequado e sem receber nenhum auxílio econômico ou possibilidade de reassentamento em local próximo, sob a justificativa de que não são detentores do título de propriedade do imóvel (ESPN, 2011).

De acordo com documentário realizado pela ESPN (Entertainment and Sports Programming Network), em alguns casos visualizados no município do Rio de Janeiro,

\footnotetext{
12 o Decreto-lei $n^{\circ} 3.365 / 41$, o qual trata das desapropriações por utilidade pública, trata do assunto referido.

${ }^{13}$ À título de curiosidade, é interessante diferenciar os conceitos de necessidade pública, utilidade pública e interesse social. O primeiro caso ocorre quando a administração defronta situações de emergência que, para serem resolvidas satisfatoriamente, exigem a transferência urgente de bens de terceiros para seu domínio e uso imediato. A desapropriação para utilidade pública, por sua vez, acontece nos casos em que a transferência é conveniente para a realização de alguma obra, mas não imprescindível e, no caso da desapropriação em função do interesse social, as circunstâncias impões a distribuição ou o condicionamento da propriedade para seu melhor aproveitamento, utilização ou produtividade em benefício da coletividade ou de categorias sociais merecedoras de amparos específicos do Poder Público (FILHO, 2010). No caso da Copa do Mundo e das Olimpíadas, as desapropriações ocorrem seguindo o critério de utilidade pública.

${ }^{14}$ Observar os artigos 26 e 33 do Decreto-lei no $3.365 / 41$.
} 
a prefeitura vem emitindo editais com o prazo de 0 (zero) dias para desocupação de determinadas áreas, havendo nítida violação aos princípios básicos do Estado Democrático de Direito. Além das próprias sequelas emocionais deixadas por um processo de desapropriação ou de remoção, as baixas (e quando existentes) remunerações e a queda na qualidade de vida agravam a situação de violação já constatada.

Contudo, embora o Poder Público esteja agindo de maneira arbitrária e autoritária em muitos casos, o Poder Judiciário em algumas situações tenta amenizar os conflitos oriundos desses problemas. É o que se observa, por exemplo, na decisão proferida em 2012 pelo Tribunal de Justiça do Rio de Janeiro ${ }^{15}$, a qual determina que os indivíduos possuidores de áreas objetos de desapropriação em função de obra vinculada à Copa do Mundo têm direito à justa indenização como forma de garantir direitos constitucionalmente delineados.

Todavia, mesmo diante de decisões que beneficiam as comunidades atingidas, o panorama geral nas cidades que serão palco dos jogos ainda é preocupante. Segundo Dossiê da Articulação Nacional dos Comitês Populares da Copa (2011), em Fortaleza, por exemplo, o bairro Mucuripe, impactado pelas obras de construção do VLT (Veículo Leve sobre Trilhos - Parangaba/Mucuripe), passou a ser cobiçado pela especulação imobiliária, sendo que dezenas de casas foram marcadas com tinta verde, sem o consentimento dos moradores, sendo isto um possível sinal de demolição.

Neste sentido inclusive, os moradores da região assinalaram a ausência de informações quanto às possíveis remoções, relatando, que as abordagens realizadas deram-se de maneira truculenta, incluindo ameaças às famílias residentes na localidade $^{16}$. Outra ofensa constatada trata-se do valor da indenização pago aos proprietários de imóveis em razão das desapropriações: diferentemente da previsão legal, de uma indenização justa, o valor oferecido varia entre quatro mil reais e trinta mil reais, quantias que são insuficientes para aquisição de uma nova moradia.

Em Porto Alegre, a situação de incerteza e insegurança de famílias que habitam lugares de interesse para obras da Copa é também uma constatação (DOSSIÊ

15 "EMENTA: Direito Constitucional e Administrativo. Desapropriação para execução do Projeto Corredor Transcarioca. Pretensão de levantamento do valor da indenização pelos possuidores. Possibilidade. O direito à justa e prévia indenização que se impõe como requisito para a imissão na posse do bem expropriado tem por escopo assegurar os direitos fundamentais à propriedade e moradia previstos na Constituição. O procedimento previsto no art. 34 da Lei de Desapropriação (Decreto-Lei no 3.365/41) possui caráter de Jurisdição Voluntária, o que autoriza o julgamento por equidade e dispensa a legalidade estrita. Precedente: Apelação 0004654-65.1999.8.19.0000 (1999.001.10214) - Des. Nagib Slaibi Julgamento: 13/04/2000 - Décima Terceira Câmara Cível. Portanto, diante da ausência de manifestação daquele que figura no RGI como proprietário que, não obstante as diversas diligências realizadas, não foi localizado. E, considerando a inequívoca prova documental de que os agravantes eram os legítimos possuidores da área desapropriada - fato reconhecido pelo próprio ente expropriante, que admitiu ter sido a imissão efetivada somente após o cadastramento dos ocupantes em programas de auxílio habitacional promovidos pela Secretaria de Habitação -, o direito à indenizatória há de ser deferido em favor dos agravantes, como forma de reparação pela perda do imóvel onde residiam com suas famílias. Precedentes do STJ. Ademais, o acervo probatório dos autos aponta fortes indícios de que os pressupostos fáticos para a usucapião encontravam-se consolidados, não havendo porque continuar impedindo o levantamento da indenização pelos agravantes, que além de possuidores, também já teriam direito à titularidade do bem. Provimento do recurso. Perda do objeto quanto ao pedido de interrupção das demolições. (Agravo de Instrumento $n^{\circ}$ 0023390-14.2011.8.19.0000, Sexta Câmara Cível, Tribunal de Justiça do Rio de Janeiro. Relator: Desembargador Nagib Slaibi, julgado em 25/01/2012).

${ }^{16}$ Neste viés, é pertinente destacar as informações coletadas pela Articulação Nacional dos Comitês Populares da Copa, que em dossiê realizado trata desse e de outros casos de violação em função de megaeventos esportivos no Brasil. (DOSSIÊ MEGAEVENTOS E VIOLAÇÕES DOS DIREITOS HUMANOS NO BRASIL, 2011). 
MEGAEVENTOS E VIOLAÇÕES DOS DIREITOS HUMANOS NO BRASIL, 2011). A Ocupação 20 de Novembro, por exemplo, desde 2007, encontra-se provisoriamente assentada em área pública nas proximidades do estádio Beira-Rio (o qual receberá alguns dos jogos do evento futebolístico). Entretanto, diante de algumas manifestações no local, como é o caso de máquinas de obras que estão avançando sobre as casas, a incerteza da desapropriação e a apreensão quanto ao que ocorrerá, uma vez que não há previsão de reassentamento definitivo, é o que impera entre os moradores do local.

Contudo, a situação mais caótica e alarmante é a observada no município do Rio de Janeiro. Neste, o processo de segregação espacial urbana é o reflexo mais evidente da maneira como as obras dos megaeventos esportivos vêm sendo conduzidas em nosso país. Segundo o Dossiê "Megaeventos e Violações dos Direitos Humanos no Rio de Janeiro", do Comitê Popular da Copa e Olimpíadas do Rio de Janeiro, as remoções e desapropriações no município são mais intensas em áreas de interesse do capital imobiliário, caso de bairros como Barra da Tijuca, Recreio, Jacarapaguá, Vargem Grande, entre outros.

Isto, aliado ao investimento em transportes que privilegiam os moradores dessas regiões e à produção de moradias populares através do Programa Minha Casa Minha Vida em áreas periféricas, não localizadas nos cinturões beneficiados com os investimentos para a Copa e para as Olimpíadas, somente vem a corroborar com a afirmação de que o que está ocorrendo é um processo de exclusão espacial e periferização das comunidades, as quais são expulsas para locais distantes de suas redes de inserção econômica, social e cultural ${ }^{17}$.

Diante do contexto apresentado, não só de criação das "cidades de exceção", na medida em que o sistema desaplica elementos normativos instituídos legalmente em prol de interesses privados, como também de ofensas a direitos fundamentais sobretudo ao direito à moradia adequada - perpetradas por instituições e agentes do Estado, vislumbra-se que, ao invés de ser feito para o povo, o esporte, através dos megaeventos, vem se apresentando como um negócio com lucros e vantagens para poucos, de modo que os eventos olímpicos e futebolísticos acabam contribuindo para a inefetividade dos direitos humanos quando comparados com a aplicação efetiva e eficaz de outros setores normativos, como é o caso dos direitos econômicos.

\section{OS MEGAEVENTOS ESPORTIVOS NA PERSPECTIVA DA ASSINCRONIA DO DIREITO}

Dentro do processo de mundialização, o qual busca estudar a multiplicidade e ambiguidade dos fenômenos que ocorrem atualmente, tentando abranger a síntese das transformações sociais e políticas contemporâneas, há que se destacar o fenômeno da assincronia do direito, estudado por Mireille Delmas-Marty (2004, p. 204). Consoante tal fenômeno, os avanços cosmopolitas - em relação aos direitos humanos - são contrabalanceados pela ideologia neoliberal, voltada para o desenfreado crescimento econômico.

\footnotetext{
${ }^{17}$ Um caso alarmante na "Cidade Maravilhosa" é o dos moradores da Comunidade Metrô-Mangueira. Nesta, algumas famílias que tiveram que sair do local foram ressarcidas com novas moradias, porém distantes cerca de $50 \mathrm{~km}$ da área original e outras restaram em meio aos escombros resultados de demolições. A região é vizinha ao estádio que faz parte do Complexo Maracanã para a Copa de 2014, quando será utilizada para estacionamento, de acordo com as exigências da FIFA. (DOSSIÊ MEGAEVENTOS E VIOLAÇÕES DOS DIREITOS HUMANOS NO BRASIL, 2011).
} 
A assincronia do direito (DELMAS-MARTY, 2004, p. 205) caracteriza-se pela diferença de velocidade dos processos de integração e de efetivação das normas internacionais de direitos humanos e/ou ambientais em relação às normas de direito do comércio. Além das velocidades serem diferentes, o tempo de integração e de efetivação de tais direitos também são diferenciados, de modo que os direitos econômicos são integrados aos ordenamentos jurídicos e efetivados no âmbito interno dos Estados de modo muito mais rápido, ou seja, em um tempo muito menor do que os direitos humanos.

Desta forma, como marca principal da assincronia em tempos de mundialização, tem-se que a evolução dos direitos humanos é lenta em comparação à celeridade da integração das normas de direito comercial. Aliás, não só o tempo de integração de direitos humanos é mais lento como também a efetivação destes no âmbito interno dos países enfrenta inúmeros obstáculos.

No caso dos reflexos dos megaeventos olímpicos no Brasil, esta barreira encontra-se clara. As autoridades brasileiras, ao incidirem nas condutas anteriormente aludidas, de criação arbitrária de leis e decretos que contrariam a legislação vigente e de desrespeito à institutos como da posse e da propriedade nos casos de desapropriação, parecem admitir que a ocorrência das Olimpíadas ou da Copa do Mundo no Brasil autoriza megaviolações de direitos constitucionalmente tutelados e megairregularidades, priorizando os lucros e ganhos econômicos em detrimento dos direitos e garantias fundamentais dos cidadãos.

Apesar de muitos esforços - através de denúncias dos casos de irregularidades e violações pela mídia e por associações da sociedade civil - para tentar atingir uma "sincronização pluralista" (DELMAS-MARTY, 2004, p.220), ou seja, para tentar acelerar a velocidade dos direitos humanos a fim de que esta seja no mínimo capaz de equiparar-se ao ritmo acelerado dos direitos econômicos, a ideologia político-econômica dominante em tempos de mundialização - o neoliberalismo - só faz reduzir o tempo da universalização e manter acelerado do tempo da globalização.

Nesta lógica, nos termos de Zygmunt Bauman (2001, p.12), a modernidade líquida ou pós-modernidade, diferentemente da modernidade sólida e pesada da sociedade de produção em massa do século passado, é a modernidade do tempo do software, da leveza e da sociedade de consumo. É neste universo do software e da liquidez que se encontram os direitos e interesses econômicos, atrelados à leveza e extraterritorialidade do capital. Os direitos humanos, por sua vez, encontram-se presos no tempo do hardware, pesado, denso, apegado ao território e com extrema dificuldade de vinculação da realidade fática com os postulados do ordenamento jurídico.

No contexto dos megaeventos esportivos, portanto, é impossível, diante da vigência do sistema neoliberal, não reconhecer a influência que tem o poder econômico e dos meios de comunicação no processo político. As ideologias neoliberais surgidas em meados dos anos 1950 e aplicadas e difundidas através dos governos Thatcher e Regan, respectivamente na Inglaterra e nos Estados Unidos, tentam reviver aspectos do liberalismo clássico de Adam Smith, sem lembrar, contudo, que os ideais das teorias clássicas do liberalismo não são capazes de se adequar de modo eficaz em todos os aspectos da sociedade pós-moderna, gerando efeitos prejudiciais, sobretudo, sobre os direitos humanos.

As políticas neoliberais são hoje predominantes e, por isso, não há como afirmar que o esporte e os eventos criados por sua motivação estarão desvinculados dos ideais e necessidades dos detentores de capital. Neste sentido as violações aos direitos humanos visualizadas configuram-se como patologias derivadas da estrutura do sistema. 
Desta forma, o neoliberalismo se caracteriza por ser a razão do capitalismo contemporâneo (DARDOT et LAVAL, 2009, p.6), não sendo somente um sistema econômico, mas sim um conjunto de discursos, práticas e dispositivos que determinam um novo modo de governo dos homens conforme o princípio da concorrência. Como elementos ínsitos de sobrevivência do sistema estão a desigualdade social e a necessidade de parecer democrático, quando na verdade não o é.

As políticas de higienização e segregação espacial que vem ocorrendo nas diversas cidades que receberão os jogos da Copa do Mundo, sobretudo no Rio de Janeiro, são a prova contundente de que os interesses do sistema capitalista não estão dissociados da realização dos projetos e obras da Copa do Mundo e das Olimpíadas. A necessidade de parecer democrático, por sua vez, é vista nos casos em que o Poder Público utiliza-se de argumentos como área de risco para justificar remoções que tem como objetivo velado a implantação de obras de projetos vinculados aos megaeventos esportivos.

Tal característica é nitidamente visualizada nos casos da Comunidade da Estradinha e do Pavão-Pavãozinho (DOSSIÊ MEGAEVENTOS E VIOLAÇÕES DOS DIREITOS HUMANOS NO RIO DE JANEIRO, 2012), ambas do Rio de Janeiro. A primeira, que reúne cerca de 350 famílias (das quais 120 já foram removidas), constituise como um assentamento situado em uma área nobre em Botafogo. De acordo com os moradores do local, a prefeitura municipal justificou a remoção alegando que a maioria das casas encontra-se em área de risco. Todavia, membros da Associação de Moradores afirmam que a maior parte do território não se encontra em área de risco, apresentando, inclusive, laudos técnicos independentes para sustentar as arguições.

No caso da Comunidade do Pavão-Pavãozinho, a prefeitura também apresentou como justificativa para remoções o risco geotécnico estrutural da região. Porém, apesar de as casas já terem sido marcadas com tinta spray, a prefeitura ainda não havia apresentado o laudo que comprovasse o risco, bem como não proporcionou discussões com a comunidade para tratar de opções às remoções.

Neste sentido, no modelo político-econômico ditado pela fase neoliberal do capitalismo, a força não está no Estado e no seu poder de gerência da sociedade, mas sim nas instituições bancárias e corporações financeiras, que controlam e manipulam os governos estatais a fim de conseguir vantagens, sobretudo econômicas, muitas vezes valendo-se de violações dos direitos humanos para efetivar lucros particulares. $\mathrm{O}$ neoliberalismo tem a necessidade de parecer democrático, mas somente é capaz de existir em razão das violações aos direitos humanos (MEZÁROS, 2008). A concentração de poder, portanto, está na raiz das violações aos direitos do homem.

\section{CONCLUSÃO}

Se não é para o povo, para quem é o esporte? Indubitavelmente a paixão do brasileiro é o futebol e a notícia de que eventos como a Copa do Mundo ou as Olimpíadas se realizarão no Brasil, invariavelmente, mexe com o imaginário ufanista do povo. Todavia, a partir do momento em que se começa a observar o legado de tais eventos para os países sede e os reflexos dos projetos olímpicos e futebolísticos para o nosso país, percebe-se que não é somente a bola de futebol que está em jogo. Pelo contrário, vislumbra-se que aquilo que é paixão popular para muitos é mero negócio para outros, com um leque de possibilidades lucrativas a ele vinculadas.

Evidentemente, diante do reconhecimento que o país terá em âmbito internacional, bem como frente aos possíveis melhoramentos das cidades em função do recebimento dos megaeventos esportivos, não se é contra a realização destes no Brasil. 
Entretanto, aquilo que se critica é o comportamento de autoridades públicas e de governos que admitem que a recepção de um evento de grandes proporções autorize violações de direitos humanos, megaendividamento público e irresponsabilidades diversas.

Este, contudo, é o paradigma político dominante no o processo de recepção dos megaeventos que o Brasil sediará. Constata-se, portanto, que tal atmosfera propiciou uma verdadeira suspensão e interrupção dos ordenamentos normativos, com a produção de vazios e contradições jurídicas, isto é, de lugares de não direito, que caracterizam o fenômeno da exceção.

Neste sentido, as remoções populacionais e as desapropriações de determinadas áreas, com nítido desrespeito a figura dos possuidores e ao instituto da posse, estão sendo feitas ou ao arrepio da legislação vigente ou com base em leis editadas naquilo de Agamben denomina de "estado de exceção", uma vez que aparentam ser legais, mas na realidade não o são. Tudo isso, obviamente, contribui para o fenômeno da assincronia do direito, uma vez que tais mecanismos dificultam a aplicação de preceitos legais, constitucionais e internacionais em favor dos direitos humanos.

Desta forma, em função dos megaeventos esportivos percebe-se o recrudescimento da "não sincronização" entre direito econômico e direito dos direitos humanos no Brasil, demonstrado por violações aos direitos humanos - sobretudo os direitos relativos à moradia. Observa-se, desta maneira, que formas de repressão e violência utilizadas pelo Estado contra a população mostram-se tuteladas "juridicamente", constituindo parte deste denominado "estado de exceção permanente", que decorre, sobretudo, da ausência de limites para a expansão dos ideais do capital. Assim, apesar dos esforços para tentar atingir uma "sincronização pluralista" (DELMAS-MARTY, 2004, p.220), a ideologia político-econômica dominante aplicada aos megaeventos esportivos só faz transformar aquilo que deveria ser para o povo - o esporte - em mero negócio, com benefícios para o setor privado.

\section{REFERÊNCIAS BIBLIOGRÁFICAS}

AGABEN, Giorgio. Estado de Exceção. Trad. Iraci D. Poleti. 2. ed. São Paulo: Boitempo, 2004 (Estado de Sítio).

BAUMAN, Zigmunt. Modernidade Líquida. Rio de Janeiro: Zahar, 2001.p.12.

BOBBIO, Norberto. A Era dos Direitos. Trad. Carlos Nelson Coutinho; apresentação de Celso Lafer. Nova Edição - Rio de Janeiro: Elsevier, 2004. p. 23.

BRASIL. Constituição da República Federativa do Brasil, 5 de outubro de 1988. Brasília: Senado Federal, 1988.

BRASIL. Decreto-lei n. 3.365, de 21 de junho de 1941. Dispõe sobre desapropriações por utilidade pública. Diário Oficial da União, Poder Executivo, Brasília, DF, 18 de julho de 1941. Acesso em 20 de set. 2013.

BRASIL. Lei n. 10.406, de 10 de janeiro de 2002. Institui o Código Civil. Diário Oficial da União, Poder Legislativo, Brasília, DF, 11 de janeiro de 2002. Acesso em 19 de set. 2013. 
BRASIL. Lei n. 11.124, de 16 de junho de 2005. Dispõe sobre o Sistema Nacional de Habitação de Interesse Social - SNHIS, cria o Fundo Nacional de Habitação de Interesse Social - FNHIS e institui o Conselho Gestor do FNHIS. Diário Oficial da União, Poder Legislativo, Brasília, DF, 16 de junho de 2005. Acesso em 20 de set. 2013.

BRASIL. Lei n. 12.035, de 01 de outubro de 2009. Institui o Ato Olímpico, no âmbito da administração pública federal, com a finalidade de assegurar garantias à candidatura da cidade do Rio de Janeiro a sede dos Jogos Olímpicos e Paraolímpicos de 2016 e de estabelecer regras especiais para a sua realização, condicionada a aplicação desta Lei à confirmação da escolha da referida cidade pelo Comitê Olímpico Internacional. Diário Oficial da União, Poder Legislativo, Brasília, DF, 13 de outubro de 2009. Acesso em 20 de set. 2013.

BRASIL. Lei n. 12.462, de 04 de agosto de 2011. Institui o Regime Diferenciado de Contratações Públicas - RDC; altera a Lei nº 10.683, de 28 de maio de 2003, que dispõe sobre a organização da Presidência da República e dos Ministérios, a legislação da Agência Nacional de Aviação Civil (Anac) e a legislação da Empresa Brasileira de Infraestrutura Aeroportuária (Infraero); cria a Secretaria de Aviação Civil, cargos de Ministro de Estado, cargos em comissão e cargos de Controlador de Tráfego Aéreo; autoriza a contratação de controladores de tráfego aéreo temporários; altera as Leis $\mathrm{n}^{\mathrm{os}} 11.182$, de 27 de setembro de 2005, 5.862, de 12 de dezembro de 1972, 8.399, de 7 de janeiro de 1992, 11.526, de 4 de outubro de 2007, 11.458, de 19 de março de 2007, e 12.350, de 20 de dezembro de 2010, e a Medida Provisória $\mathrm{n}^{\mathrm{o}}$ 2.185-35, de 24 de agosto de 2001; e revoga dispositivos da Lei $\mathrm{n}^{\mathbf{0}}$ 9.649, de 27 de maio de 1998. Diário Oficial da União, Poder Legislativo, Brasília, DF, 10 de agosto de 2011. Acesso em 21 de set. 2013.

BRASIL. Lei n. 12.663, de 05 de junho de 2012. Dispõe sobre as medidas relativas à Copa das Confederações FIFA 2013, à Copa do Mundo FIFA 2014 e à Jornada Mundial da Juventude - 2013, que serão realizadas no Brasil; altera as Leis $\mathrm{n}^{\text {os }}$ 6.815, de 19 de agosto de 1980 , e 10.671 , de 15 de maio de 2003; e estabelece concessão de prêmio e de auxílio especial mensal aos jogadores das seleções campeãs do mundo em 1958, 1962 e 1970. Diário Oficial da União, Poder Legislativo, Brasília, DF, 8 de junho de 2012. Acesso em 22 de set. 2013.

BRASIL. Tribunal de Justiça do Rio de Janeiro. Sexta Câmara Cível. Desapropriação para execução do Projeto Corredor Transcarioca. Pretensão de levantamento do valor da indenização pelos possuidores. Possibilidade. Agravo de Instrumento $\mathrm{n}^{\mathrm{o}}$ 0023390-14.2011.8.19.0000. Agravante: Denise Cassiano Barreto e outros; Agravado: Município do Rio de Janeiro. Desembargador Nagib Slaibi. Julgamento em 25/01/2012. Rio de Janeiro, 25 de janeiro de 2012. Disponível em: http://www1.tjrj.jus.br/gedcacheweb/default.aspx?UZIP=1\&GEDID=0003820784A6BDE340491B9D8F 100B4D8B4EC9C4031B272E. Acesso em 01 de setembro de 2013.

DARDOT, Pierre; LAVAL, Chrsitian. La Nouvelle Raison du monde: Essai sur la Societé Néolibérale.Paris. La Découverte. 2009.p.6.

DELMAS-MARTY, Mireille. Les forces imaginantes du droit (II): Le Pluralisme Ordonné. Paris. Seuil. 2004.p.204-206.

DOSSIÊ DO COMITÊ POPULAR DA COPA E OLIMPÍADAS DO RIO DE JANEIRO. Megaeventos e violações dos direitos humanos no Rio de Janeiro. 2012. Disponível em http://comitepopulario.files.wordpress.com/2012/04/dossic3aa-megaeventos-e- violac3a7c3b5es-dosdireitos-humanos-no-rio-de-janeiro.pdf. Acesso em: 30 ago. 2013. 
DOSSIÊ DA ARTICULAÇÃO NACIONAL DOS COMITÊS POPULARES DA COPA. Megaeventos e violações dos direitos humanos no Brasil. 2011. Disponível em: http://raquelrolnik.files.wordpress.com/2011/12/dossieviolacoescopa.pdf. Acesso em: 30 ago. 2013.

ESPN. Desapropriação no Rio para a Copa e Jogos Olímpios de 2016 - ignoram leis e cidadãos. Disponível http://www.youtube.com/watch?v=d0CVZ6s1zNA\&feature=related. Set. 2011. Acesso: 20 set. 2013.

FARIAS, Cristiano Chaves de., ROSENVALD, Nelson. Direitos Reais. 7 ed. Rio de Janeiro Lumen Juris, 2011.p.41-47.

FILHO, José dos Santos Carvalho. Manual de Direito Administrativo. 23 ed. Rio de Janeiro: Lumen Juris, 2010.p.364.

HOSHINO, Thiago et GORSDORF, Leandro Franlin. A Lei Geral dos interesses particulares. Le Monde diplomatique Brasil. Ano 5/Número 52, 2012.

MÉSZÁROS, Istvan. Marxismo e direitos humanos, in Filosofia, ideologia e ciência social. Trad. Ester Vaisman. SP: Boitempo, 2008.

WERNECK, Felipe et LEAL, Luciana Nunes. Brasil tem 11,42 milhões vivendo em moradias irregulares. Reportagem disponível no endereço eletrônico

http://www.estadao.com.br/noticias/geral,brasil-tem-1142-milhoes-vivendo-em-moradiasirregulares,813842,0.htm. Dez, 2011._Acesso 20 set. 2013.

WOOD, Ellen Meiksins. Democracia contra capitalismo: a renovação do materialismo histórico. Trad. Paulo Cezar Castanheira. SP: Boitempo, 2003. 